\title{
The will to love that makes a difference
}

\author{
MARCIANO ESCUTIA \\ Universidad Complutense de Madrid \\ mescutia@ucm.es
}

ORCID: 0000-0002-2725-0726

\begin{abstract}
This essay deals with the question of what really makes human beings exceptional. It is argued that it is a special kind of love that ultimately distinguishes humans from other animals. Although other kinds of considerations, preferably cognitive ones, have most often been invoked to make such a distinction, these might eventually be found to be, at least in part, a matter of degree and not something qualitatively different, as argued here with respect to this type of love. Arguments from both scientific and philosophical sources are brought to bear on the question.
\end{abstract}

Key words: Benevolent love; Personhood; Human Dignity.

I have a fifty-eight year old friend who has ten natural children, already grown up, with three teenagers still at home. This would not make headlines -not that it is necessary- if, besides, he had not adopted three other younger ones, two with Down syndrome and one with a neurological disorder. He and his wife will have to care for them until their old age when they could live in a well-deserved, more peaceful and comfortable situation. This doesn't need to make the headlines either in spite of its extraordinariness and the underlying depth of ... what precisely? Because this is the key thing here, 
both difficult to put one's finger on and characterize, at least from a purely naturalistic outlook.

As it will be argued, this is an example of a special kind of love which uniquely characterizes our species. This perspective has not often been used to qualify the exceptionalness of human beings. My goal is to contribute some thoughts about the uniqueness question from the unfrequented viewpoint of a capacity to love in a particular way.

\section{A Natural love?}

There are instances of non-human animals which show unexpected feeling toward other (non) human creatures (I trust the latter word will reveal where I stand from the beginning): a dog toward a cat, of all animals; an orangutan befriending a dog; a lion licking and caressing a woman; a grizzly bear playfully fighting with a man; not to mention many examples of dolphins and humans, all of them of animals with a certain level of intelligence, either kept in captivity or accustomed to frequent and progressive human contact (or even tamed, in some cases). All of these are instances of something akin to what C. S. Lewis (1960) characterized (in Greek) as Storge. There is even the example of the video gone viral in the internet of a dog befriending a restless little boy with Down syndrome and pouring affection all over him. Yes, one of those human individuals that we all get very tender and compassionate about on meeting them, but who are aborted at very high rates in the West before reaching their ninth month of existence since their conception, (it can be easily checked in the Web). We even give them awards at movie ceremonies, as it happened not long ago in Spain, or see them make headlines when modelling clothes on a catwalk platform (those lucky enough to survive).

The example from our first paragraph (that about my adopting friend) and the preceding one are not exactly of the same kind. I think the former shows a qualitative leap over the others, apart from all the differences that go with being and living in a world of human beings. This is not a "purely natural” love, for those of one's kin, with no "selfish gene” (Dawkins 1976) 
involved and no apparent evolutionary advantage to be had from it. Let us not forget that, in nature, where selection and the survival of the fittest reigns at large, its weakest members are often left to die by their own parents or are even eaten by them (those same lions who were so tender with their human caretaker). Furthermore, adopting those children does not seem to be the response of a dopamine-driven brain seeking new experiences either. Neither of high oxytocin levels inducing increased generosity to connect with strangers in a blind search for happiness; hardly the result of a neurotransmitter addiction. Perhaps one should put this couple under an fMRI machine to see what lights up in their brains in order to find an answer to our perplexity regarding such unusual behavior (though not that infrequent in kind if one cares to research it). I wonder what they would answer if they were asked how their brains took that decision.

I don't expect they would consider the whole thing as somehow predetermined by their genomes and their interaction with their environment, education, upbringing, family situation, historical circumstances and cultural surroundings, though these must have played their part as well (I suspect most people tend to be unconscious of their "real", brain-produced, subconscious or atavistic evolutionary motives). However, I know how they would verbalize it because I have asked them. It is something they have experienced phenomenologically, that they are conscious of, in terms such as "whole family decision". They believe that their human motives are such as "sharing their well-being with less fortunate ones", "a chance to do specific good to others" -typical "reasons of the heart", although they also think they are supernaturally oriented, in that they see the will of God there. These are all expressions which may have their own spot in the brain and one might suppose that rescuer dolphins or compassionate dogs would also utter... if only they could.

And scientists could not contradict them because they cannot even tell us what a decision is physically: firstly, they only know that decisions take place in the brain, that they seem to result from its activity and that they are arrived at after a preceding unconscious period; secondly, because decisions are taken in a brain that may be governed by quantum physics, as the 
synapses between neurons conduct signals using parts of atoms called ions, subject to Heisenberg's indeterminacy principle. This says that subatomic particles do not occupy definite positions in space or time and we can find out where they are only as a series of probabilities about where they might be. It really does away with determinism and leaves room for the decisions of a free will, which in its turn may (freely) choose to be "determined" by that higher love, whatever its physical concomitants.

My friend's is a kind of love not explainable by a combination of chemicals originated in certain parts of the body -although it must also have its organic reflection. Even if a natural compassion -probably felt as well by certain animals, like some of those mentioned above- may be part of it, that is clearly not the whole story. In fact, many weaklings in the animal kingdom, whose mothers seem to feel pity for them at first, end up all alone and are eventually killed by others.

No doubt natural compassion is also involved here, but there is more to it: this is a love that looks at people with affection from the inside, with good will, not as replaceable biological units. A love which treats everyone as ends in themselves, as human individuals who cannot be sacrificed at the whim or for the sake of a majority. This love may have its natural basis in human nature, in an innate or well entrenched belief that everyone has intrinsic value no matter what their material characteristics may be (beauty, intelligence, refinement, class, position, prestige, standing of any kind...). Innate does not necessarily mean wholly genetic in this case; in fact it does not look like it at all.

\section{Human intrinsic value}

The sense of believing that everyone has intrinsic value is inscribed in most (sane) human individuals. Experimental proof of it is a variant of Jarvis Thomson's (1985) Trolley problem, in which a great majority of people tested worldwide would not push an imaginary obese man off a bridge and onto some rails to sidetrack an upcoming train, thus killing him directly, in order to save five people ignorant of what is coming at them. I am not 
aware that the test has been done using a non-human animal, let's say a cow, instead, but I am quite certain that the results would be radically different with the same comprehensive type of sample. Perhaps the owners (mark the word) of that cow might react differently, especially if it were their pet as well. Still, theirs would be an affection they have put there, not (mostly) something directly inspired by the animal itself to lead anyone to the point of comparing it to a human individual.

The problem is that nowadays many people treat other individuals, especially their children, as if they owned them and gave them their value, thinking that they may bring them into the world when they want to and through any means they deem proper. Thus, their children's intrinsic value is the loser for it and the whole matter becomes clouded in the bud. Many of us have witnessed the kind of traumas that such a mentality can produce in many of those "owners" when their precious possessions may not respond later in life as they would have liked to and are left alone by them.

Admittedly, in some societies, where children have been raised in an atmosphere in which a human individual life's intrinsic worth has been erased, apparently through violence (there is always something more and deeper to it), the results of the above experiment might be different. The terms of the test might not even make sense at all, as, no doubt, an upbringing component is always there encompassing most human instincts. Still, we cannot think of that intrinsic value as something we put there ourselves, as with the cow above, but rather as a reality we just discover and should acknowledge somehow.

\section{Personal dignity}

Some people, at least in western culture, may even verbalize that intrinsic value by saying something like "you can't do that to a person" and that is probably the key to it. The concept of person is a controversial one since it is not deemed to be intuitively universal but rather just an old western philosophical construct; still, if preferable, one could talk about "a human individual" instead. However, going from acknowledging the intrinsic 
worth of an individual to loving him/her is a big leap, since there must be an antecedent good will (latin bene-volere, whence, benevolence). There is a presupposed intermediate step, though, called reverence (cf. Sheed 1953). All sane individuals experience it toward other fellow humans, whatever their individual value or lack thereof, position, capacities, virtues or accomplishments, which are not the source of it. Reverence must be part of the essence of being a person/human being, providing justification for the phrase "all men are (created) equal", meaning equally men. But, just what is reverence precisely?

There is another concept which has traditionally been called human dignity, not to be confused with others such as composure, elegance, cleanliness or maturity, let alone physical attractiveness or pride, as does Pinker (2008) in his invective against it. This notion, of the essence of humanity, is taken to be the source of the aforementioned reverence and a derived consequence of being a person. It presupposes considering mankind as, potentially at least, the only species with intelligence, will and confirmed consciousness about being conscious; and, as a result, with complete freedom -even from instinct- and, concomitantly, a moral sense and responsibility. Otherwise one is bound to believe that all these properties are mere illusion, epiphenomena, artifacts of brain evolution or simply products of evolutionary psychology. Not that a person's dignity depends upon these factors but they are presuppositions to understanding it; however, there are human individuals who, through no fault of their own, have lost them or never had them and still possess dignity.

Those who reject this notion tend to supplant it by autonomy and so are likely to think of intrinsic worth in terms of capacities, like the capacity to self-government. Thus, the number of those accepted as human is restricted, with some handicapped individuals being deprived of their dignity due to lack of autonomy, such as the three adopted ones above. That is the reason why few of them come to fruition nowadays in our "autonomous" west. This implies that in order to be considered a person, one must have an advanced level of brain function, a completely developed and normally functioning cerebral cortex. Thus, many human beings would not be persons and one 
might choose to abort them, for example, once their genetic condition is established. This should logically apply also to children in general since it is possible to conclude that infants do not develop a sense of self-awareness, until about one year of age, let alone being autonomous. As the neo-natologist and emeritus professor at University College of London John Wyatt (2009) points out, within that framework, non-persons would include fetuses, newborn babies and infants who lack self-awareness, as well a large group of children and adults with congenital brain abnormalities, severe brain injury, dementia and major psychiatric illnesses.

Wyatt points out how for Princeton moral philosopher Peter Singer persons include only those who may want to continue living or make plans for the future because they grasp the meaning of their future existence. Thus, one cannot end their lives against their will, unlike that of those who are not people because they do not have that awareness. Following this line of reasoning, says Wyatt, not just a neonate or young infant might qualify as non-persons, but also an elderly human with Alzheimer's, a human with profound brain damage or learning difficulties, and an individual with a severe and untreatable psychiatric illness.

However, many neuroscientists would argue that our conscious awareness is merely an epiphenomenon of brain functioning. Following this line of reasoning, consciousness, Wyatt goes on ironically elsewhere, which would seem to make us aware of that autonomous self, has no causal importance, "it is merely part of the froth on the surface of unconscious brain activity" (Wyatt 2014). In fact they argue that our sense of a single continuing self is an artifact created by our brains to help our evolutionary survival. Thus, Wyatt concludes, "there is no self at all, there is no ghost in the machine, there is just the machine" (Wyatt 2014). I suppose a machine has neither dignity nor deserves reverence.

Only when there is reverence, with its foundation on the reality of being a person, with human dignity, understood as a human being no matter what their self-awareness and autonomy may be, can one foster good-will toward others in "one's froth". Otherwise, benevolence would be impossible or merely the accompanying result of well-being, a nice digestion, comfort- 
ableness or self-satisfaction, at most the result of an evolved "reciprocal altruism" (Trivers 1971). This nothing to do with real love, which resides in the will -no doubt with some frontal lobe correlate- and, as such, can be commanded. It follows intelligence, acknowledging the intrinsic value or dignity of every human individual, even the most depraved ones, who may have made themselves subjectively unworthy of it.

\section{Spiritual love}

However, this belief can only be true if its reason is not found in this world of things practical, calculable, replaceable - material or biological. Neither would it be in a different universe part of a possible multiverse but still with some form of material energy as its basis. The intrinsic dignity of any human being or person, no matter at which stage or condition in their life (i.e. an unborn or Down syndrome child, a paraplegic or an adult with Alzheimer's disease) can only rest on the fact of having been created by God in his own image, on who one is, not on what one can accomplish autonomously. Besides, if we do not think of persons as creatures endowed with a co-substantial embodied immortal spirit and wanted individually by God, not mere accidents of a biological chain, we run the risk -also pointed out by Wyatt- of falling into an undesired dualism separating body (which may be there in its integrity at the disposal of the inner self) and conscious awareness (the inner self), which may be absent because of brain damage or just sleep. ${ }^{1}$

One's personhood is not "cortical": it does not disappear if the cerebral cortex starts to malfunction. In Christian thinking, as Wyatt also remarks, whatever happens to us in the future, whatever disease or accident may befall our central nervous system, even if we are struck down by dementia or enter a persistent vegetative state, we remain the same person, with the same immortal spirit, perhaps without conscious awareness, but uniquely wanted by God. There may be no autonomy then but some kind of dependence is part and parcel of human life from the beginning of our conception: were we

1 In that sense, the functional distinction between body and mind, the natural self, on the one hand, and spirit, the supernatural one, on the other, reveals itself as very useful. 
not ourselves then when clinging to our mother's endometrium, depending on her benevolence? And what about later on, in the continuum of our life, when we may have to take care of her or we have to be taken care of by others? A universe made up of completely independent beings would be a selfish, elitist and horrible autistic nightmare, a kind of futuristic robotic singularity some are already predicting.

This dignity-based reverence makes it possible to love others not because of their lovableness, or their human category or a good turn they may have done to us but because they are created in the image of the Creator, persons, with or without autonomy or intact cognitive capacities. This love is the gift of oneself for the good of others - it is wholly other-oriented and directed to their welfare and benefit. A love rooted in pleasing oneself is self-centered and possessive - it is a selfish love that takes from others rather than giving to them. It is possessive of one's children, unconsciously thought of as if they were ours rather than a gift we have been entrusted with and, as such, "planned and obtained" when and how we choose and not in the way in which they have the right to come into this world (and also "let go" -as in the English euphemism for sacking someone- of their clinging to us for continued existence).

This love is similar to what Lewis (1960) calls agape, a love purified of all self-seeking dross, which may be concomitant with likings or fondness for particular people but doesn't depend on them. It has nothing to do with feelings though it doesn't exclude them. What is more, it leads one to encourage the latter in oneself and even triggers them when they are not naturally present by acting on it, because this is a love with deeds, not necessarily with feelings (which cannot be commanded to experience). These "will to love" deeds have a feedback effect on those natural affections, increasing them. The opposite is also true: acting on natural dislikes instead produces increasing psychological distance from those people so disliked. ${ }^{2}$ As Lewis (1943) also puts it: "the more cruel you are, the more you will

2 This is consistent with something widely attested in psychiatry, the capacity of the mind to change the brain when focusing on wholesome things through natural or supernatural motives (cf. Schwartz \& Begley 2002). 
hate; and the more you hate, the more cruel you will become-and so on in a vicious circle forever" (p. 117).

Dr. Robert Sapolsky (2010) -a professor at Standford university and a leading neuroscientist and primatologist, a "strident atheist", in his own words- confesses his perplexity about this type of love, which extends even to the unlovable and unforgivable, and considers it to be the most defining feature about who we are, still more that others such as a far deeper theory of mind (degrees of abstraction and spatio-temporal diverse hypothetical states or events), language, communication, cooperation and sexual behavior. He gives the example of Helen Prejean, the nun attending to death row convicts made famous by the 1995 film "Dead man walking”. The answer she gives to the frequent question about the reason why she does this ministry ("The less forgivable the act, the more must be forgiven; the less lovable the person is, the more you must find the means to love him") strikes Sapolsky as "the most irrational, magnificent thing we are capable of as a species", whereby we go far past the things we can do with respect to theory of mind, empathy or culture. For him, this is the ultimate reason for our uniqueness as a species. Note that he characterizes it as something that goes beyond our cognitive faculties, which could never explain it.

It is very difficult to conceive how a love like this, which may be heroic, far beyond our own natural capabilities, even reaching out to one's enemies, ${ }^{3}$ could spring up just as part of the activity of a material brain and encompassing hormones. Nor is it easy to imagine what evolutionary advantage it might have towards spreading an impossible mutation which could have given rise to such quirk in an ancestral brain. ${ }^{4}$ There is something here away

3 Like that of the woman who not only forgives the man, on death row at present, who killed her daughter and grand-daughter but gives him support in his life-time prison, as described in the film Human (2015) by Arthus-Bertrand. This film contains many examples of the type of love we are addressing here -along with painful (in)human experiences of which mankind is also capable- and of the yearning for it by people from all cultures and walks of life.

4 To quote some pop evolutionary psychology, one of the Kryptonites in the movie Man of Steel (2013), played by actor Antje Traue, who fights Superman, explains to him, how they, a people more evolved than humans, have learned that evolution is incompatible with a sense of morality. 
and above emotions, natural affections or mere rationality, which points to something qualitatively different from the result of material evolution, to some kind of spiritual principle not susceptible of evolving into being. It is comparable, in another field, to what Chomsky (2015) thinks about the origin of language. He conceives of it not as an evolution from previous skills or abilities, though it may recruit some of them, but rather as something that comes into being as such, probably along with our mathematical ability, with no predecessors. The difference here is that the latter responds, according to the famous linguist, to a sudden genetic mutation in an individual and the love we are describing seems more like an infused gift from outside our own realm, though capable of becoming incarnate in humanity. ${ }^{5}$ An individual may or may not be conscious of this capacity, not develop it or even forfeit it temporarily before coming to fruition because of their upbringing. Still the capacity remains, unlike one of those biological instincts subject to critical or sensitive periods, which, if not exercised or provided input to, does not develop properly. In any case, it would really be rare in someone who had not refined his spirit before by previous acts of generosity or dedication to others in their lives.

As humans, then, we are all capable of both giving and receiving this type of love, no matter what our other capacities may be: giving, that is, provided we have not degraded our humanity; receiving, if there is someone around us with some spiritual life. This kind of love makes us similar to the God of the New Testament, who is Love (1 Io 4, 16). Without going into its deeper theological consequences, this means that God's essence is that kind of disinterested love which doesn't depend on satisfying a need or feeling. It is a pure outpouring for the sake of the persons so loved, capable of giving one's life for them, with nothing material entering into it.

If, as the Bible says, we are made in the image and likeness of God (Gen $1,27)$, because God infused his spirit in man (Gen 2, 7) and God's essence is Love, our inmost core then is made up of the spirit of God, that is, of love, and a love of the kind described. Therefore, what is most specifically human

Isn't that what it is meant about Jesus Christ when defined as "Love incarnate"?

ScientiaetFides $6(1) / 2018$ 
is that interchange of unselfish, disinterested love, and living by and growing in it is what humanizes us most, much more than being experts in neurology, physics, linguistics or evolutionary psychology; or having accomplished all kinds of career goals, let alone displaying a beautiful or voluptuous body. And this is rather encouraging, something we are all endowed with, no matter our intelligence or sophistication, and are capable of even if confined to a wheel-chair or slowly losing our mind. This may smack to some of "slave morality", the sort Nietzsche -with his "will to power"- loathed so deeply. He was the champion of the famous autonomy (though he may have felt happy that his sister did not act upon it in his final bed-ridden days).

\section{Conclusion}

The philosopher T. Nagel (2012), again another atheist, explains very clearly how there must be more to humans than the sole result of natural (evolutionary) processes:

If we continue to assume that we are parts of the physical world and that the evolutionary process that brought us into existence is part of its history, then something must be added to the physical conception of the natural order that allows us to explain how it can give rise to organisms that are more than physical. The resources of physical science are not adequate for this purpose, because those resources were developed to account for data of a completely different kind (p. 46).

The spiritual love that has been dealt with here is one of those properties that do not seem to be amenable to such physicalist explanations. With Sapolsky, this is really the unique feature, qualitatively different, which sets us apart from other non-human animals. We are the only ones capable of this will-to-love love; even those with a poor intellectual life for lack of exposure to an education or an environment conducive to it. Still, even those deprived individuals, if mentally normal otherwise -as spirit in our case is destined to be incarnate- are capable of a disinterested, heroic love 
as well as of addressing their creator, the source of it, something other animals are unable to do ${ }^{6}$.

We may once reach that singularity mentioned before, with the human era at an end once super-intelligent robots are made. These, in turn, may build even better machines with the intelligence of man left far behind, at the mercy of large computer networks. Those who think that robots may get to have the same faculties and emotions of a human being are wrong about one thing at least: the type of love described here, whose substance cannot be programmed or recreated because it cannot be analyzed into components, as is the essence of spirit, even when incarnate. I just hope they don't come to be regarded as persons for all their self-awareness and autonomy. In any case, I doubt they will ever adopt dependent, handicapped robots and care for them, a clear sign of the loss of humanity at heart ${ }^{7}$.

\section{References}

Alejandro Bonmati, Asier Gomez-Olivencia, Juan Luis Arsuaga, Jose Miguel Carretero, Ana Gracia, Ignacio Martinez, Carlos Lorenzo, Jose María Bermudez de Castro \& Edouald Carbonell. 2010. "Middle Pleistocene lower back and pelvis from an aged human individual from the Sima de los Huesos site, Spain.” Proceedings of the National Academy of Sciences. Retrieved at: http://www.pnas.org/content/107/43/18386.full.pdf.

Chomsky, Noam. 2015. Why only us. Cambridge, Massachusetts: MIT Press.

Dawkins, Richard. 1976. The Selfish Gene. Oxford: Oxford University Press.

Jarvis Thomson, Judith. 1985. “The Trolley Problem.” The Yale Law Journal 94, 6:1395-1415

6 As Josemaria Escriva put it: "religion is the greatest rebellion of men, who refuse to live like animals, who are dissatisfied and restless until they know their Creator and are on intimate terms with him" (Friends of God n. 38).

7 Something already present in our most primitive ancestors. The Homo Heildebergensis, one of the hominids found in Atapuerca (600,000 to 200,000 thousand years old), buried some subjects who were seriously ill and physically or mentally handicapped. Those individuals had not only not been abandoned but had been taken care of in their life time and even fed by others. As concluded by one of the researchers there, what those remains and their ailments show is that those hominids were already very human because they buried their dead, cared for others and cooperated with them. Not a bad summary to characterize humanity. (Bonmati, A. et al. 2010). 
Lewis, Clive Staples. 1953. Mere Christianity. Geoffrey Bles.

Lewis, Clive Staples. 1960. The four loves. Geoffrey Bles Publishers.

Nagel, Thomas. 2012. Mind and Cosmos: Why the Materialist Neo-Darwinian Conception of Nature Is Almost Certainly False. Oxford: Oxford University Press.

Pinker, Stephen. 2008. “The Stupidity of Dignity.” The New Republic. Retrieved May $15^{\text {th }} 2017$ at: https://newrepublic.com/article/64674/the-stupidity-dignity.

Sapolsky, Robert. 2009. “The uniqueness of humans.” Ted Talk. Available (June 2017) at: https://www.ted.com/talks/robert_sapolsky_the_uniqueness_of_humans

Schwartz, J. \& Begley, S. 2002. The Mind and the Brain: Neuroplasticity and the power of mental force. New York: Regan Books.

Sheed, Frank. 1953. Society and sanity. London: Sheed and Ward Ltd.

Singer, Peter. 1985. "Persons and non-persons." In In Defense of Animals, edited by Peter Singer, 52-62. Basil Blackwell.

Trivers, R.L. 1971. “The evolution of reciprocal altruism.” Quarterly Review of Biology 46:35-57. doi:10.1086/406755.

Wyatt, John. 2009. Matters of Life and Death. Nothingham: IVP Books.

Wyatt, John. 2014. What is a Person? Neuroscience, Human Identity and the Christian Faith. Lecture at the London Institute for Contemporary Christianity. Available (June 2017) at: https://www.youtube.com/watch?v=ZRIddOvdH_4\&t=12s. 